\title{
Total Synthesis of (+)-13-Deoxytedanolide
}

\author{
Lisa D. Julian, Jason S. Newcom, William R. Roush* \\ Department of Chemistry, University of Michigan, Ann Arbor, MI, 48109 \\ e-mail:roush@umich.edu
}

Supporting Information:

Selected ${ }^{1} \mathrm{H}$ and ${ }^{13} \mathrm{C}$ NMR spectra for key intermediates 


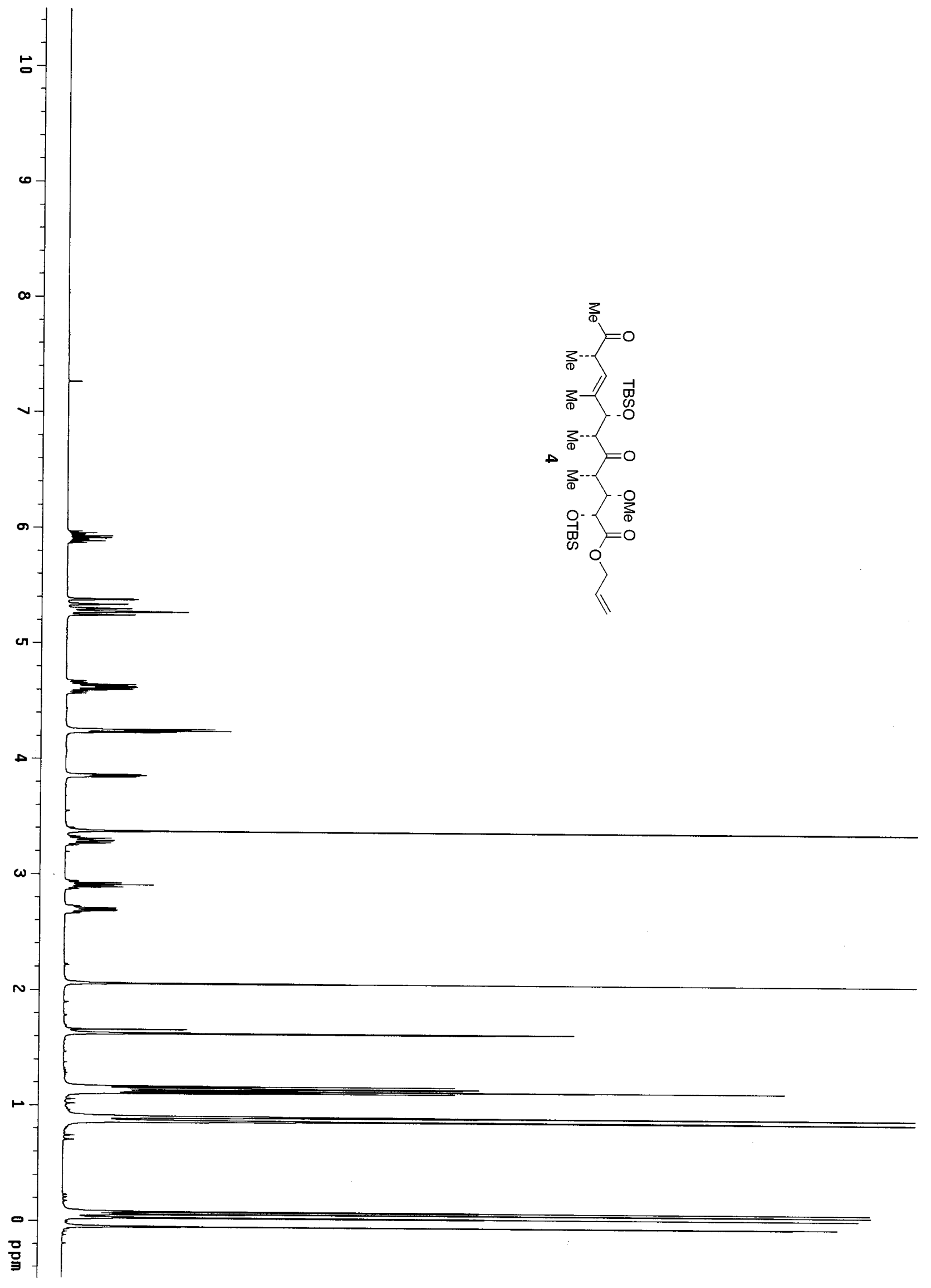




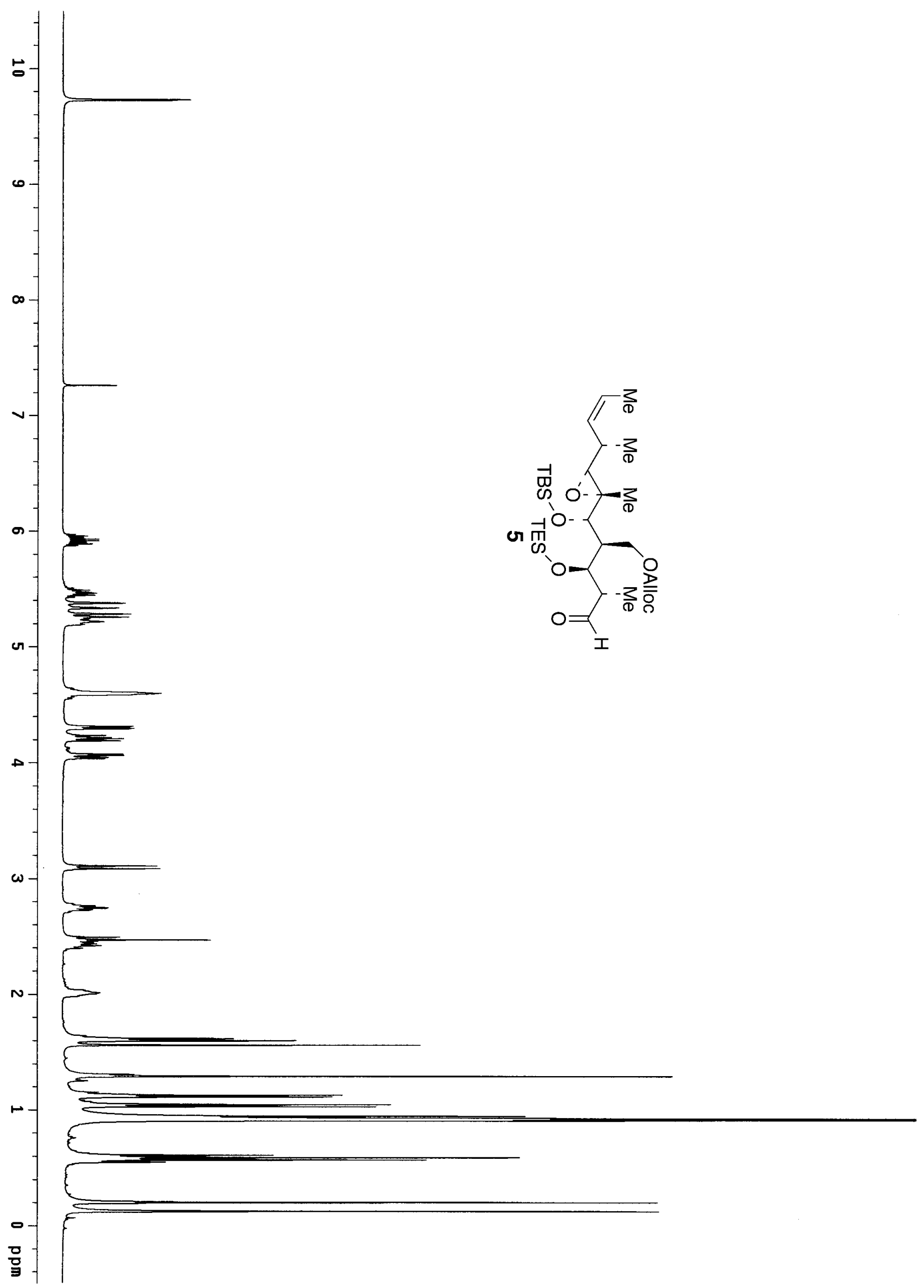

SI-13 


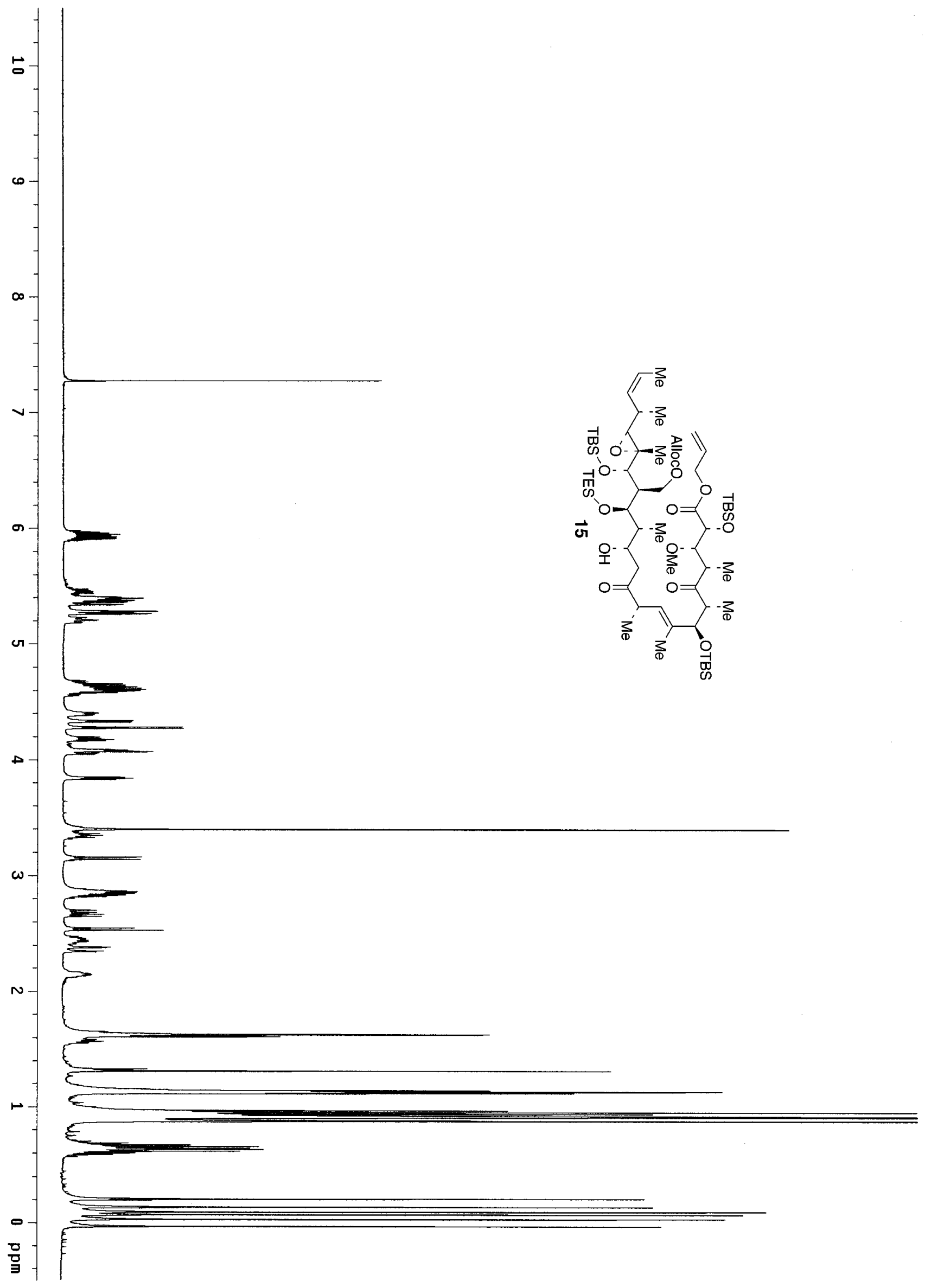




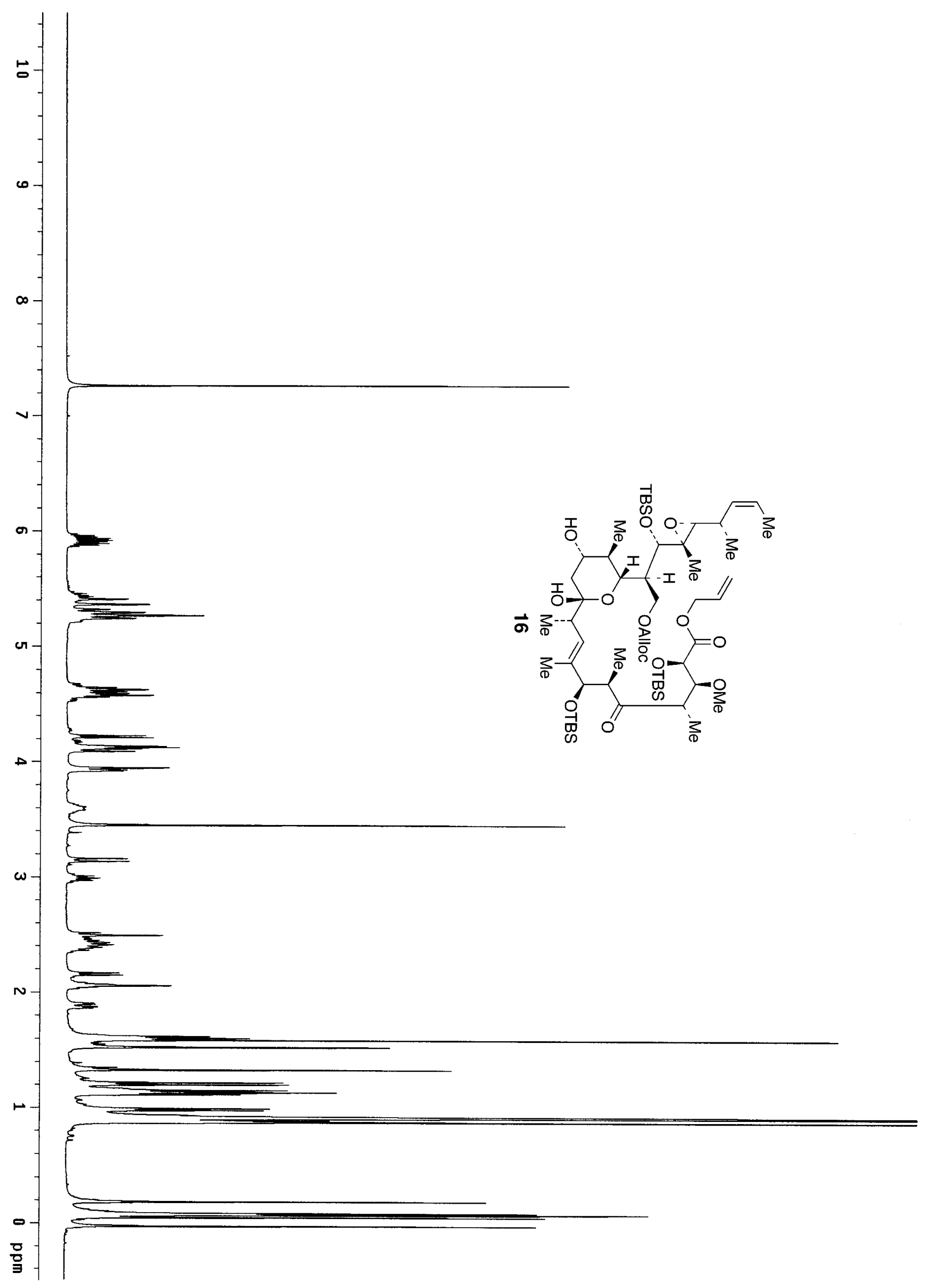

SI-15 


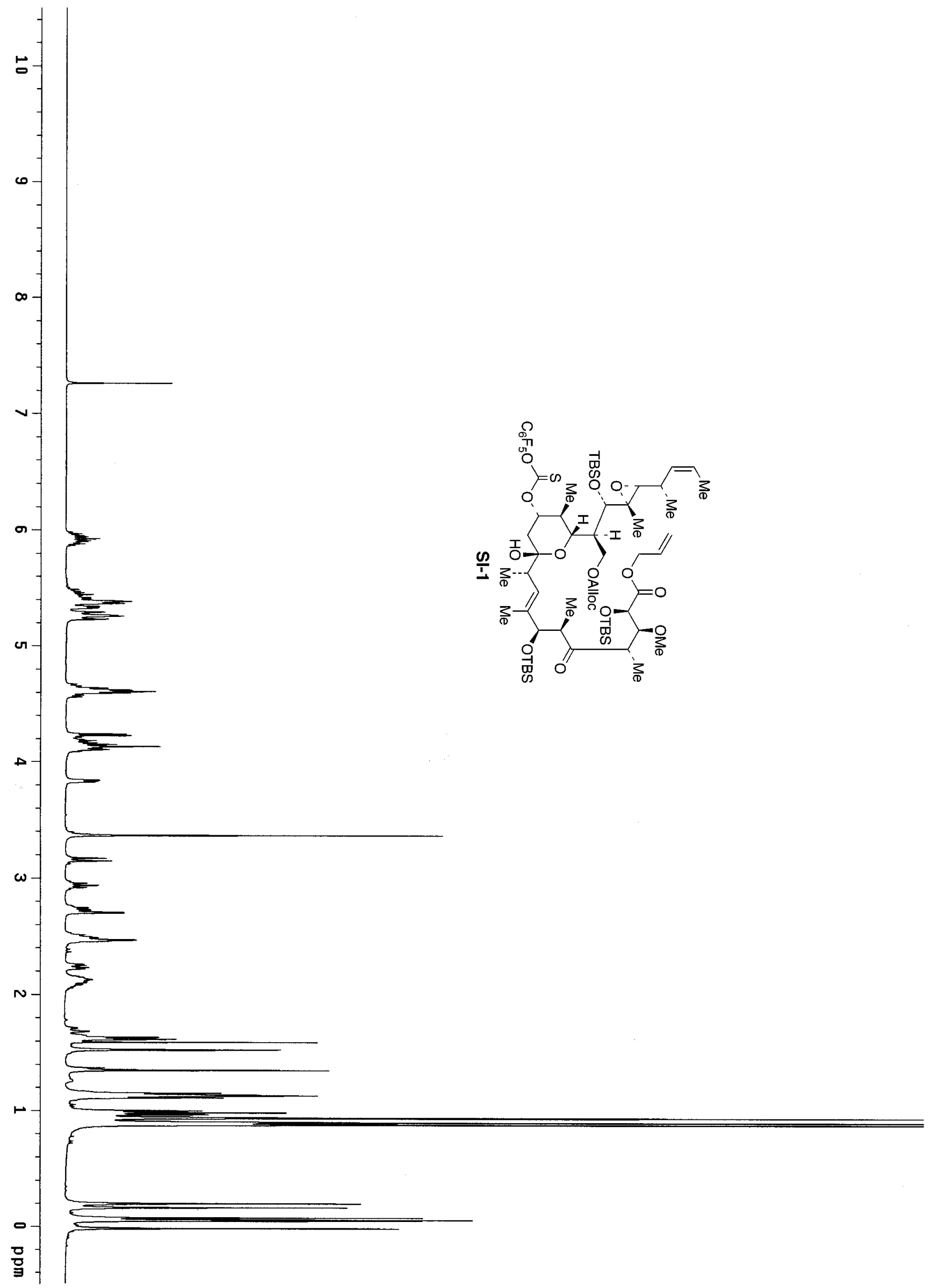




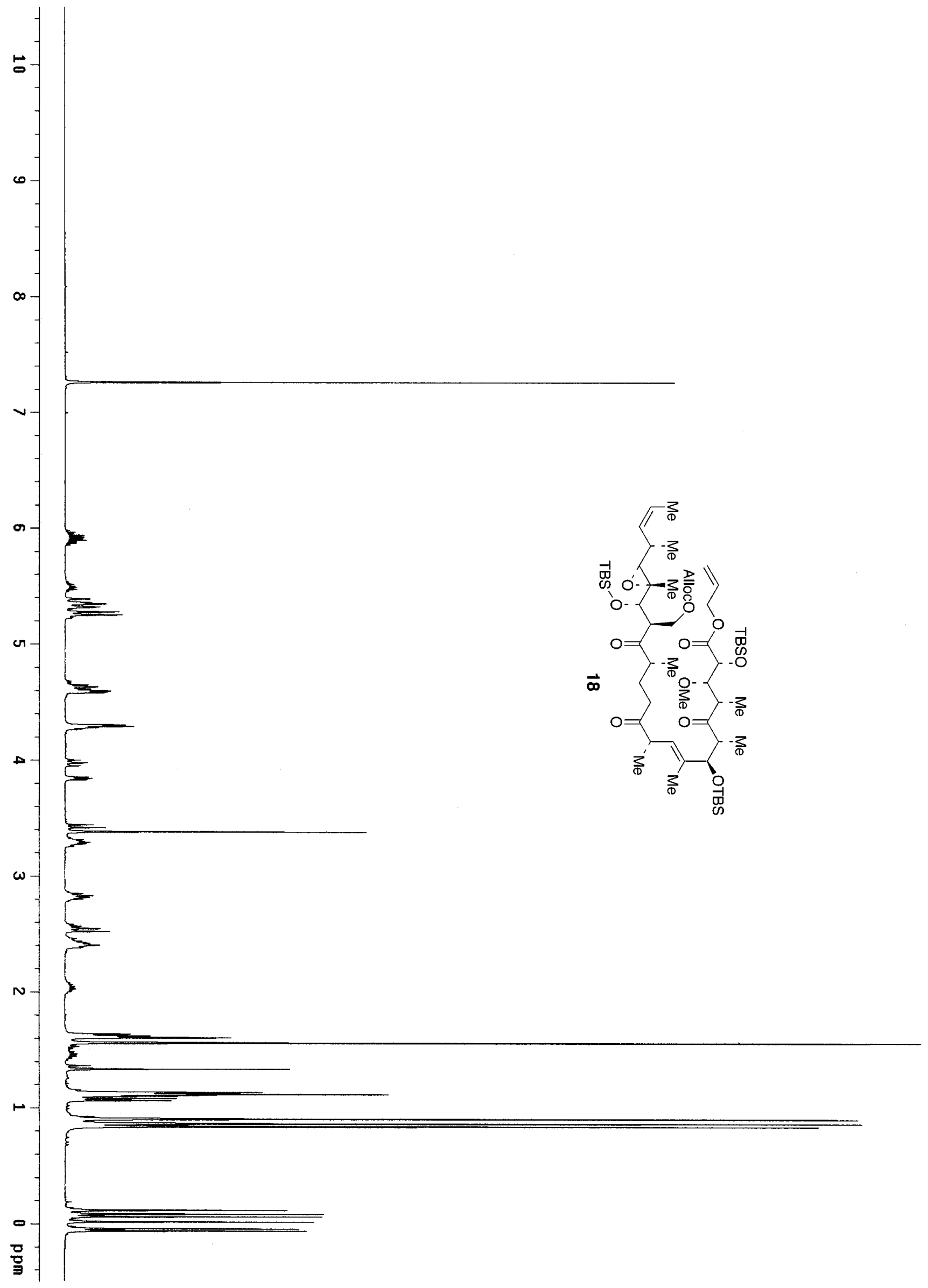




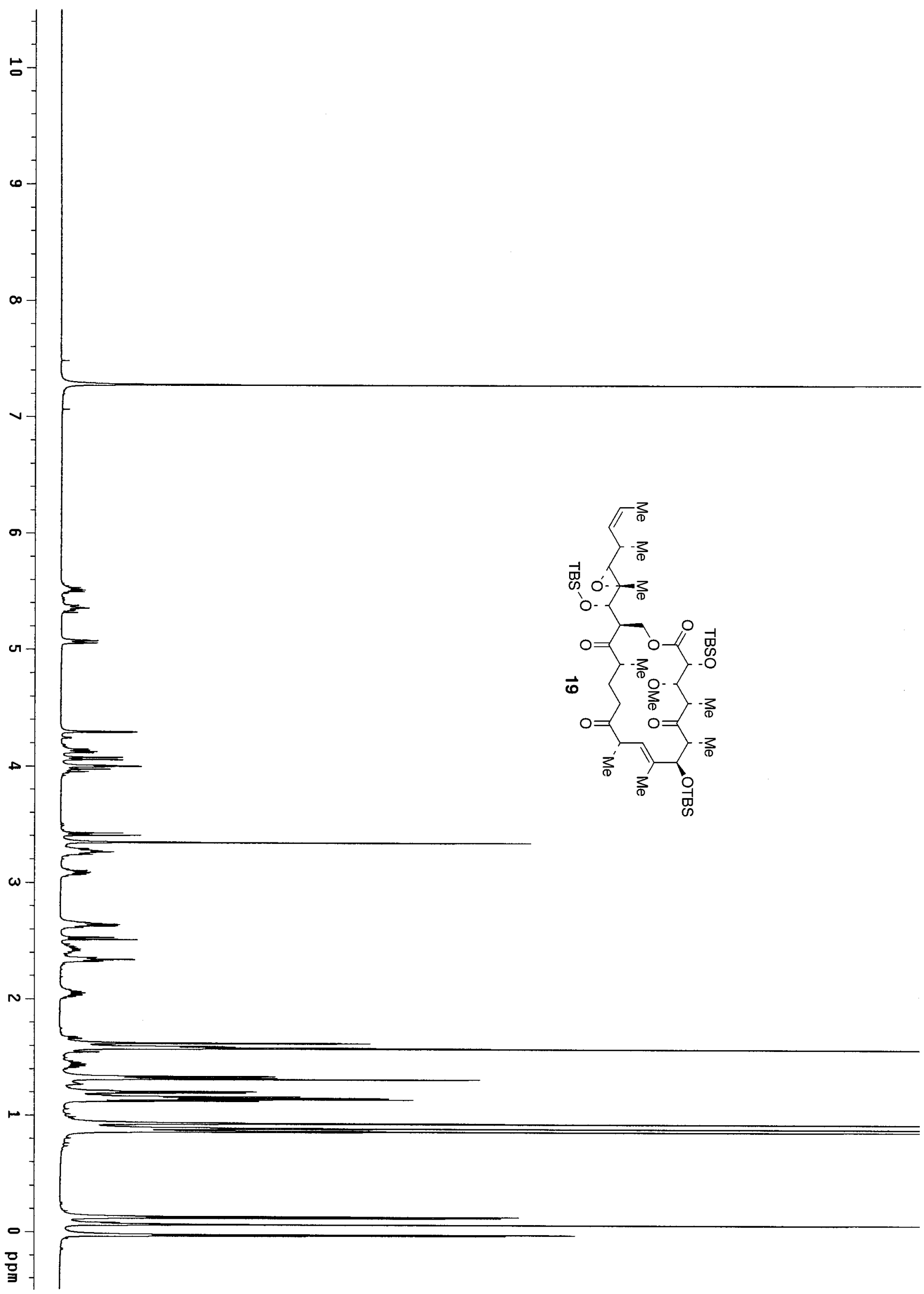

SI-18 


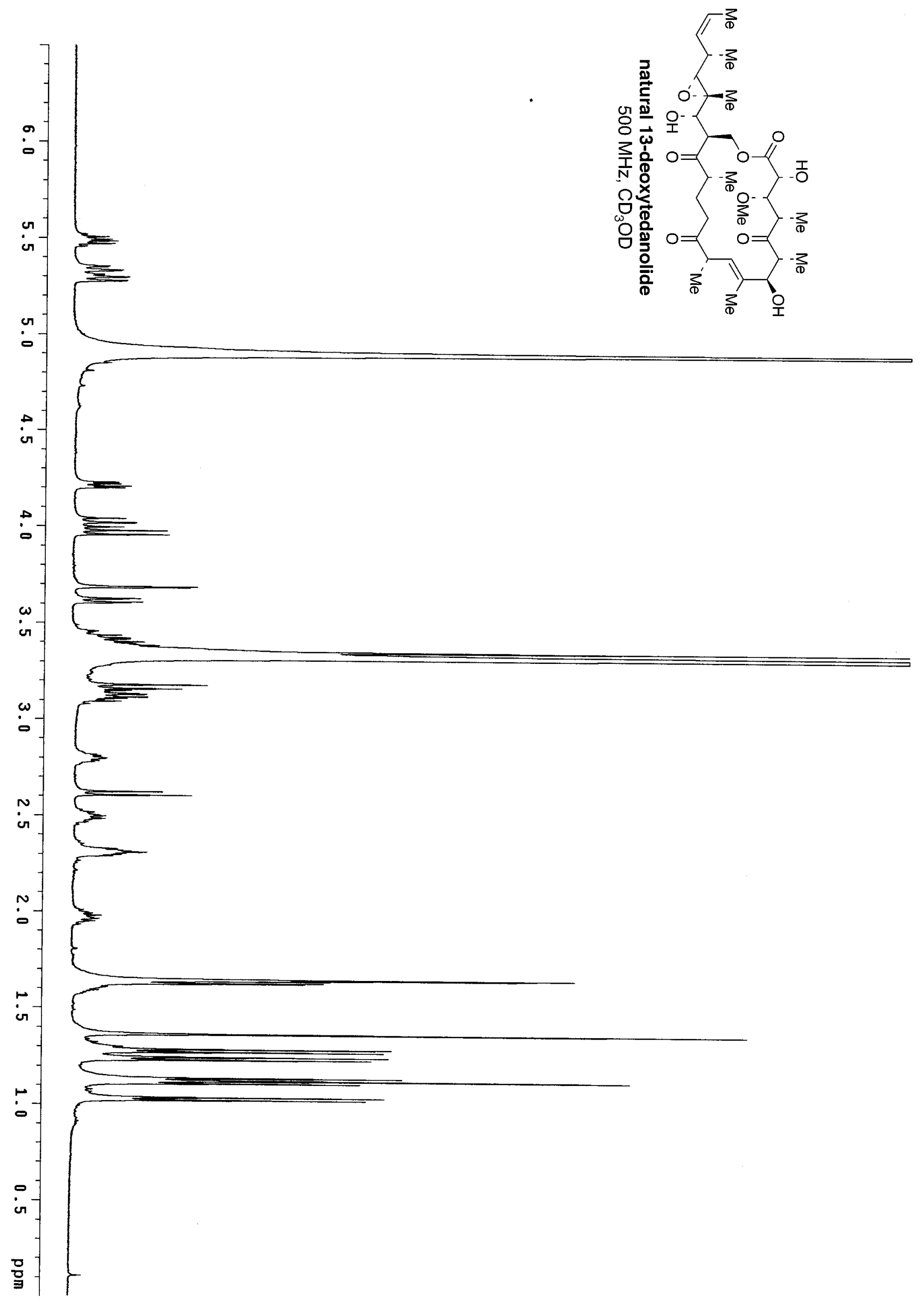




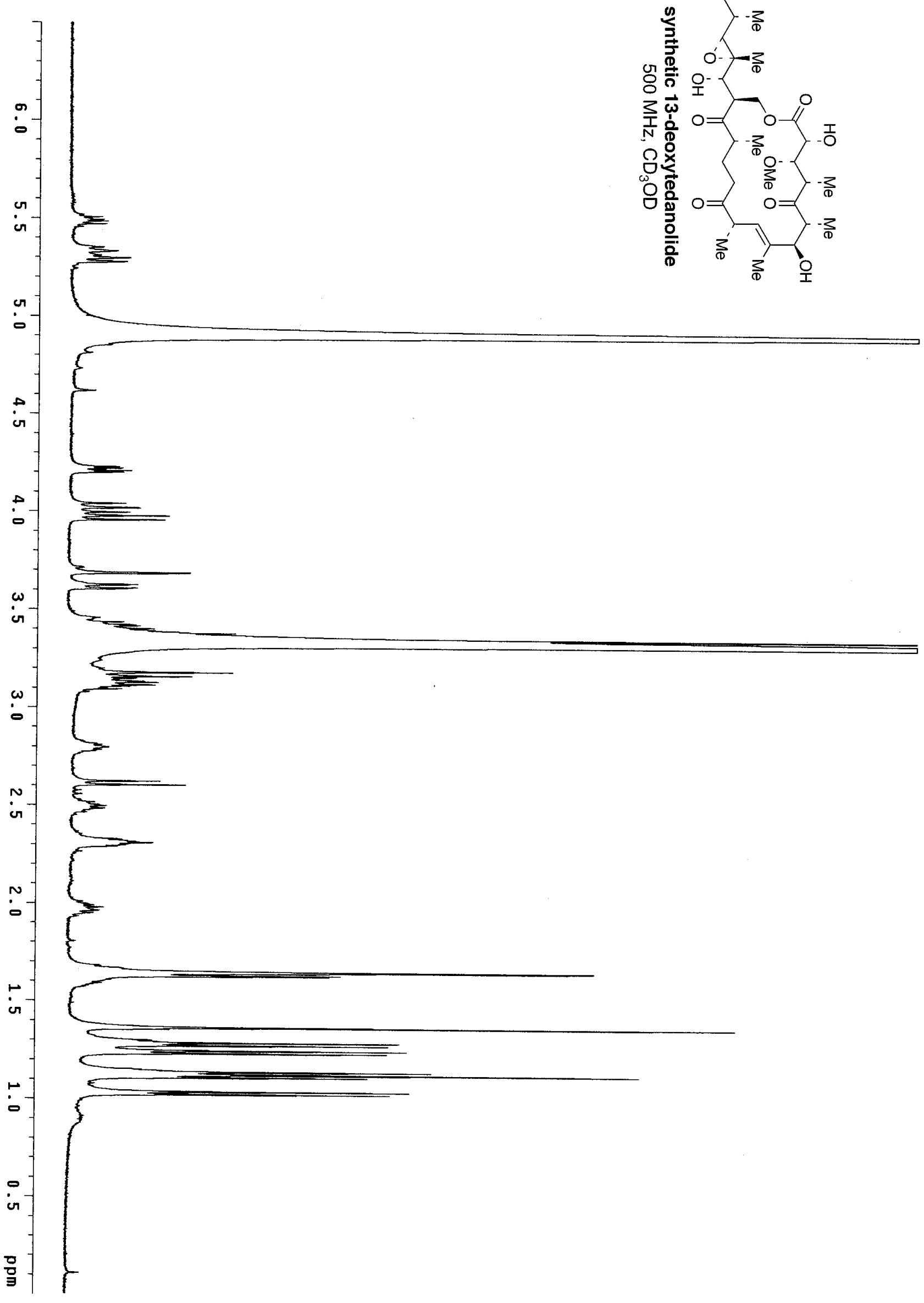




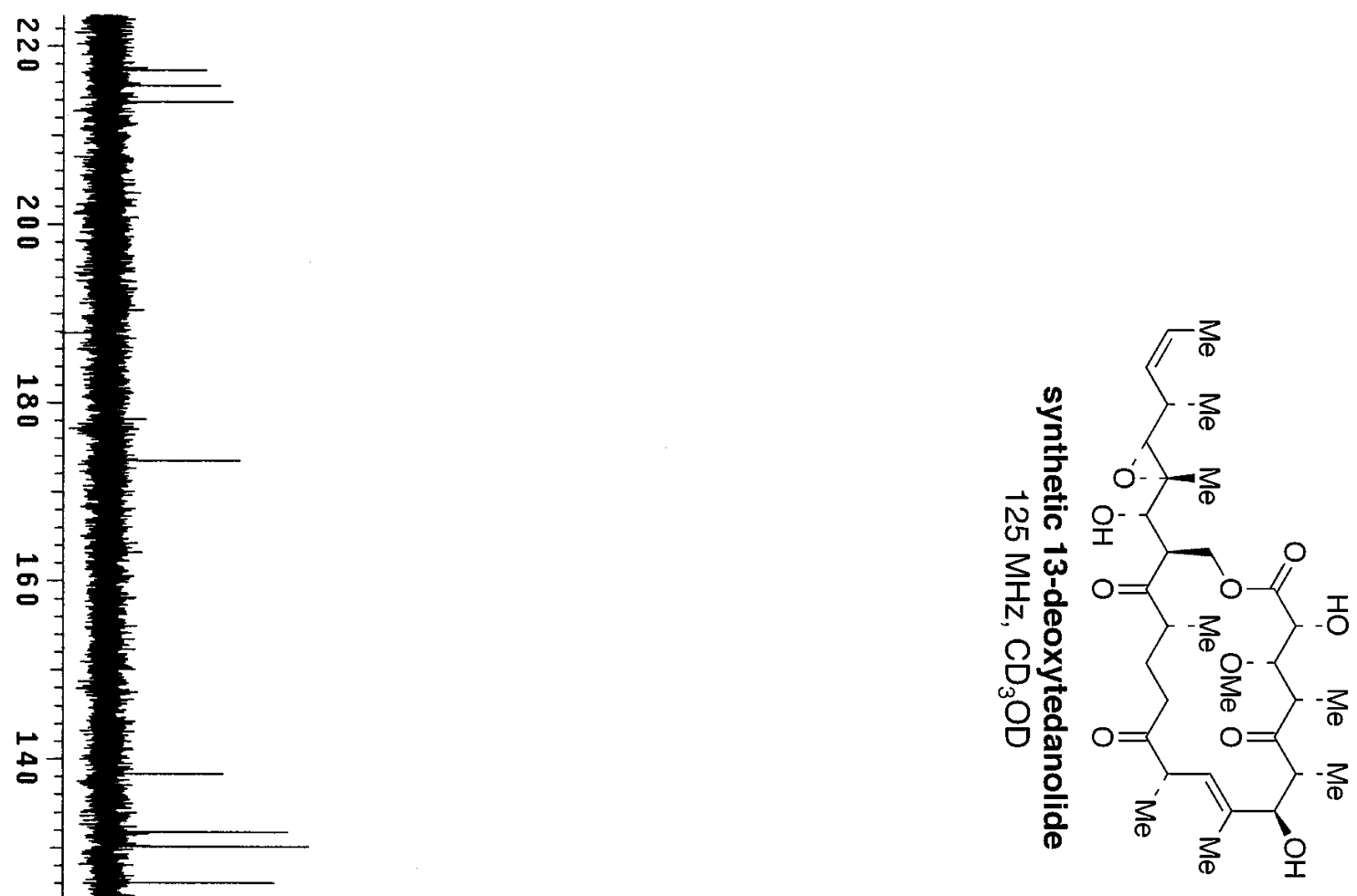

